\title{
Editorial
}

-Querida, ¿no querrías un poco más de té? -la instó, apremiante, la Liebre Marcera. -Si todavía no he tomado nada -exclamó Alicia, en un tono ofendido-, no puedo tomar más.

-Querrás decir que no puedes tomar 'menos' -le corrigió el Sombrerero -: es difícil tomar menos que nada... ipero es tan fácil tomar más! Alicia en el país de las maravillas, Lewis Carroll.

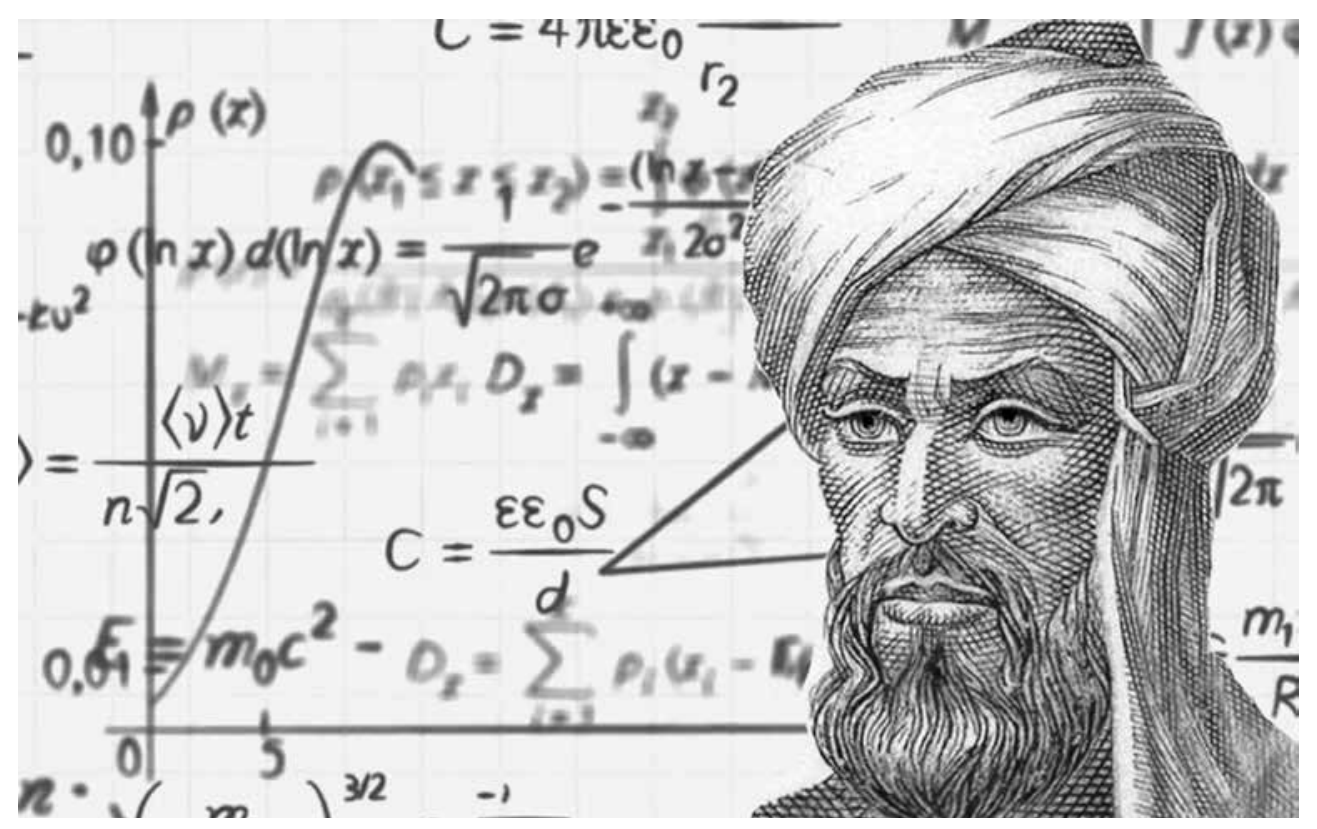

El origen de los números, como de toda la construcción del lenguaje en su expresión simbólica, ha tenido relación con tradiciones míticas. Es asombroso que sobre el año 700 estuviésemos aprendiendo a contar con el cero gracias a los indios (aunque fuese un árabe quien trajera la noticia a Occidente: Muhammad ibn al-Khwarizmi, 780-850). Y que muy pronto, en el siglo de Newton y Leibniz estemos inmersos en el teorema del límite, tejiendo el cálculo diferencial, contando infinitos acotados.

Poco a poco, tanto el carácter mítico como la relación directa entre el número y la realidad, se ven desplazados con los nuevos mundos autónomos de la realidad matemática. De una relación sígnica uno a uno (ángulos para definir la figura que los nombra), los números desarrollan un diálogo entre ellos, otro con la naturaleza, uno más con las relaciones entre los seres humanos. Ya alguien dijo: "Las matemáticas son la búsqueda de los números primos". Es decir, la matemática moderna es la búsqueda de lo no evidente con los girones de racionalidad creada por los primeros juegos de nuestro contar incipiente. Una historia análoga va de la geometría de Euclides, a la necesidad de una geometría más allá del plano, deseosa de continuidad y de otros espacios, tras Euler y Gauss, tras la nueva mirada de la geometría diferencial 
(riemanniana), con una cima en la cultura matemática, cuyo nombre reclama el respeto de un Quijote para las batallas en el mundo de los axiomas: Hilbert. Ya los ojos no alcanzan para mirar los planos de la arquitectura del mundo. Las proposiciones sintéticas kantianas son herramientas para caminar sobre la tierra; pero las proposiciones analíticas, la complejidad del lenguaje matemático capaz de fundar mundos y fenómenos no observables, no visibles a nuestros ojos sino habitados en laberintos elaborados por la razón, capaces de llevarnos a combates de molinos y gigantes no vistos antes sobre el plano cartesiano, son el fundamento de los diálogos de otra dimensión, como la topología. El nuevo lenguaje ha fundado mundos nuevos, los nuevos mundos siguen reclamando un nuevo lenguaje. En esa lucha incesante entre lenguaje y realidad nos perdemos. Ya Don Quijote nos ha advertido, la realidad es la que soñamos.

La matemática es un palacio para el viaje cuyo tiquete no requiere de grandes inversiones. El amor, la rutina y el método, son los amuletos para la jornada. Ramanujan nos da fe de esta experiencia, como Fischer en el ajedrez. Ambos poblaron sus mundos de laberintos y luego la realidad inmediata fue hostil, el paisaje se doblaba por coordenadas de tiempo. El espacio de Hilbert desnuda la necesidad de Pessoa de multiplicarse en muchos seres ante la imposibilidad de vivir en un cuerpo mutado en una orquesta sinfónica cuyos sonidos ya no puede dominar un solo hombre. Entonces los ojos sucumben, la flor es un ramillete y el ramillete es todo el universo bajo patrones matemáticos complejos, la sucesión de Fibonacci florece en nuestro jardín. La simetría del arte escapa a la experiencia inmediata.

Einstein intenta tomar su autobús pero las piedras que ha pisado un segundo antes en el pequeño barranco al lado la carretera lo abstraen; ahora, todo el universo habita bajo sus zapatos, en ese instante el sistema se mueve, su ser ha sido atrapado por el lenguaje. Fischer, el monstruo del ajedrez que venció un siglo de dominio ruso en los torneos internacionales, viaja de incognito de motel en motel antes de enfrentar el campeonato mundial, su equipaje es un tablero de ajedrez; no puede cumplir citas ni hablar con nadie, ha olvidado el calendario e incluso su nombre en el pasaporte, no puede jugar de modo ortodoxo y pierde; es la sangre que necesita su cuerpo para el salto al vacío, para el dominio de esas geometrías desconocidas de sus caballos siempre al ataque bajo el ritmo implacable de su reloj al acecho del miedo del otro. Los dos, Einstein y Fischer son poetas, son artistas, los dos descubren el lenguaje del tiempo y del espacio bajo las cifras.

Más que contar dibujamos el mundo, de la esfera de Tolomeo, una esfera cerrada finita, pasamos al orden de Copérnico con el Sol en el centro, pero con un sistema abierto al infinito, a la incertidumbre. El movimiento reclamó a Newton la necesidad de un lenguaje acorde a la nueva complejidad de la física, el mundo del cálculo infinitesimal viene para nombrar nuevos objetos. El lenguaje funda realidad. No es otra la ruta a la que recurre Gaudí, no podía terminar su Sagrada Familia en vida, necesitaba dejar algoritmos para que otros arquitectos continuaran su legado. Otros deberían leer el ritmo de su mano, la secuencia del color, las formas de los trozos, su olfato para comprender la curva en el horizonte; todo, cuando su cuerpo muerto no pudiese dar la orden. 
En la hipermodernidad (Lipovetsky) mapeamos las posibilidades de ocurrencia, pasamos del riesgo a la incertidumbre, domesticamos la naturaleza, a los números. $\mathrm{El}$ azar es aquello que no dominamos. Ahora, la matemática ha mutado en varias lenguas, ya es muy compleja para ser el dominio de todos sus caminos. Muchos hombres, muchas mujeres trabajan sin saberlo sobre la misma pregunta; casi seguro desde diversos ábacos. No es una coincidencia a despreciar que desde Pitágoras, culturas distantes trataron a la hipotenusa como cuerda, lo que delata la necesidad práctica de la pregunta en sus orígenes. La historia de la matemática es ya un laberinto a la manera de la Torre de Babel trasmutada en biblioteca...

El universo (que otros llaman la Biblioteca) se compone de un número indefinido, y tal vez infinito, de galerías hexagonales, con vastos pozos de ventilación en el medio, cercados por barandas bajísimas. Desde cualquier hexágono se ven los pisos inferiores y superiores: interminablemente (La biblioteca de Babel; Borges, J. L.).

Cierro esta invitación a viajar por esta entrega de la revista Papeles dedicada a las matemáticas con un poema de mi libro Ceniza de luna, dedicado a esa arena infinita de los números.

\section{Números de arena}

En las puertas de la iglesia

persiste el tráfico de los sueños,

una moneda compra la esperanza.

Todos jugamos el pan

a la confusión de los dados.

Y el ciego vendedor de lotería

palpa los números,

piedras de arena

en la tumba sin nombre.

Está puesto el reloj:

llenamos de ojos la noche,

los remos son muletas

para remontar la sangre,

hasta que el mar es un río

donde compartimos las orillas.

Los niños en el ábaco

renuevan la piel de las cifras

ensartando calaveras

en los hilos de la memoria.

En la arena

hay huellas de agua. 